\title{
Hemodynamic instability in septic shock
}

\author{
Véronique Lapointe, MD · Drago Jocov, MD · \\ André Denault, MD
}

Received: 15 May 2009/Accepted: 5 August 2009/Published online: 23 September 2009

(C) Canadian Anesthesiologists' Society 2009

Septic shock is a common cause of hemodynamic instability. To optimize management, causative mechanisms need to be determined early in the process. Early diagnosis and intervention remain very important aspects in establishing a favourable outcome. Fortunately, early diagnosis can be facilitated with good clinical acumen and aided with bedside echocardiography, as illustrated in the following case. The Research Ethics Committee of the Montreal Heart Institute granted approval for the use of the related echocardiographic images for research and educational purposes.

A 30-yr-old woman presented with mild hypotension, high fever, and acute renal failure 3 days after instrumental vaginal delivery. She had experienced mild pharyngeal discomfort and non-hemorrhagic diarrhea for $24 \mathrm{hr}$ on the second puerperal day. She was first diagnosed with sepsis of unknown origin and was given broad-spectrum

Electronic supplementary material The online version of this article (doi:10.1007/s12630-009-9168-9) contains supplementary material, which is available to authorized users.

\author{
V. Lapointe, MD \\ Department of Medicine, Université de Montréal, \\ Montreal, QC, Canada \\ D. Jocov, MD \\ Department of Radiology, Université de Montréal, \\ Montreal, QC, Canada
}

\author{
A. Denault, MD ( $\varangle)$ \\ Division of Critical Care, Centre Hospitalier de l'Université de \\ Montréal, Department of Anesthesiology, Montreal Heart \\ Institute, Université de Montréal, 5000 Bélanger Street, \\ Montreal, QC H1T 1C8, Canada \\ e-mail: andre.denault@umontreal.ca
}

antibiotic therapy and aggressive fluid resuscitation. Computed tomography of the abdomen did not reveal an infectious focus.

The patient's condition deteriorated over the ensuing $48 \mathrm{hr}$, and she was admitted to the intensive care unit requiring escalating doses of vasopressors and mechanical ventilation. Her septic condition was further complicated by hematological abnormalities (elevated white blood cells and thrombocytopenia), renal failure (with the need for renal supplementation with continuous veno-venous hemofiltration $[\mathrm{CVVH}]$ ), elevated liver enzymes, and profound lactic acidosis. Her blood cultures were positive for Group A $\beta$-hemolytic Streptococcus. When the diagnosis of streptococcal toxic shock syndrome was established, the patient received penicillin, clindamycin, and a 3-day course of immunoglobulins.

Over the following 2 days, hypotension and organ failure improved moderately. However the vasoactive support and CVVH could not be completely withdrawn. At this time, transthoracic echocardiography revealed diffuse left ventricular hypokinesia. Dobutamine was then initiated (Fig. 1). Subsequently, the patient's general status improved. The vasoactive medications and mechanical ventilation were weaned over the next 3 days, and she recovered with the only late complication being desquamation of extremities 10 days after admission. The patient returned home 21 days after admission with only mild toe necrosis.

The streptococcal toxic shock syndrome is a severe form of septic shock caused by the Streptococcus pyogenes bacteria and characterized by massive activation of systemic cytokines by bacterial toxins. Septic shock is the last of a continuum of circulatory abnormalities caused by the host inflammatory response to an infection (Table 1). It is defined as severe sepsis with hypotension refractory to volume resuscitation. ${ }^{1}$ Infectious agents trigger the release 
A



C

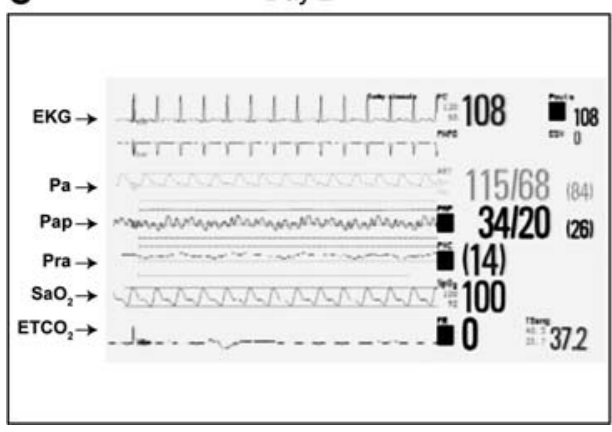

Fig. 1 Hemodynamic and echocardiographic variables on two different days for a patient is septic shock. a On day \#1, the arterial blood pressure (Pa) was $82 / 53$ with a mean of $63 \mathrm{mmHg}$. b At that time, a parasternal short axis with M-mode view is shown (see video \#1). The anteroseptal wall corresponds to the upper component (arrow 1) and the inferior wall corresponds to the lower component (arrow 2). The use of M-mode helps to characterize motion over time. c On the

of inflammatory cytokines, such as tumour necrosis factor$\alpha$, interleukin- 6 , and nitric oxide. Clinical manifestations result from a combination of systemic effects, including abnormal vasodilatation, diminished relative and absolute volumes, depressed biventricular function, and altered microcirculation. These cytokines induce decreased vascular resistances and increase venous compliance, causing the mean systemic venous pressure (Pms) to significantly decrease (Fig. 2a). They also increase capillary permeability and, in turn, promote capillary leakage of intravascular fluids. This state of relative hypovolemia further decreases the Pms. The toxic circulating mediators also cause depressed myocardial contractility, which contributes to cardiovascular compromise (Fig. 2b). Left ventricular hypokinesia can be present in up to $60 \%$ of septic shock cases and can be identified at the bedside using echocardiography. ${ }^{2}$ Right ventricular systolic dysfunction can also be present. ${ }^{3}$ Both conditions will lead to elevated right atrial pressure (Pra) and, consequently, to reduced venous return. Finally, intra-abdominal hypertension can be found in up to $82 \%$ of septic shock patients. ${ }^{4}$ In such a situation, the increase in resistance to venous return (Rvr) can also contribute to reduced cardiac output. Therefore, all three determinants of venous return (reduced


following day, after initiation of dobutamine, the arterial pressure had normalized and the patient could be weaned from the ventilator. $\mathbf{d}$ The same parasternal view is shown after the use of dobutamine. Note that the motion of the anteroseptal wall was more pronounced following dobutamine administration (see video \#2). EKG electrocardiogram, $\mathrm{ETCO}_{2}$ end-tidal carbon dioxide, $\mathrm{Pap}$ pulmonary arterial pressure, $\mathrm{Pra}$ right atrial pressure, $\mathrm{SaO}_{2}$ oxygen saturation

Pms and increased Pra and Rvr) may contribute to the hemodynamic instability in septic shock.

The rapid recognition and management of septic shock is essential to prevent its high mortality rate of $40-70 \%{ }^{1}$ Delay in initiation of antimicrobial therapy is associated with a high mortality rate of up to $10 \%$ per hour. ${ }^{5}$ Suspicion of septic shock should initiate immediate action and the source of infection should be sought by analysis of the patient's medical history, by physical examination, and by laboratory and radiological means. Within the first $6 \mathrm{hr}$ after the onset of shock, initial resuscitation should be aimed at obtaining central venous pressures between 8 and $12 \mathrm{mmHg}$, mean arterial pressure $>65 \mathrm{mmHg}$, urine output $>0.5 \mathrm{~mL} \cdot \mathrm{kg}^{-1} \cdot \mathrm{hr}^{-1}$, and central venous (superior vena cava) oxygen saturation $\left(\mathrm{ScvO}_{2}\right)>70 \%$ (Fig. 3). ${ }^{6}$ Large volumes of fluid and vasopressors are used to achieve these therapeutic goals. A mean arterial pressure (MAP) $>65 \mathrm{mmHg}$ in a usually normotensive patient has been shown to provide adequate organ perfusion. This is important because autoregulation in vascular beds can be lost when the mean arterial pressure decreases below a certain point. Tissue perfusion then becomes linearly dependent on systemic blood pressure. ${ }^{7}$ Appropriate endorgan oxygenation can be estimated by monitoring lactate 
Table 1 Definitions used in sepsis-related illness
SIRS systemic inflammatory response syndrome,

$S B P$ systolic blood pressure, $M A P$ mean arterial pressure, $\mathrm{PaCO}_{2}$ partial pressure of arterial carbon dioxide, $\mathrm{PaO}_{2}$ partial pressure of arterial oxygen, $\mathrm{F}_{\mathrm{I}} \mathrm{O}_{2}$ fraction of inspired oxygen

\section{SIRS}

$\geq 2$ of the following:

- Increased heart rate $\left(>90 \mathrm{~min}^{-1}\right)$

- Increased respiratory rate $\left(>20 \mathrm{~min}^{-1}\right)$ or $\mathrm{PaCO}_{2}<32 \mathrm{mmHg}$ or use of mechanical ventilation

- Increased temperature $\left(>38^{\circ} \mathrm{C}\right)$ or decreased temperature $\left(<36^{\circ} \mathrm{C}\right)$

- Increased white cell count $\left(>12000 \mathrm{~mm}^{-3}\right)$ or decreased white cell count $\left(<4000 \mathrm{~mm}^{-3}\right)$ or $>10 \%$ immature (bands) form

2. Sepsis

SIRS + proven or suspected infection

3. Severe sepsis

Sepsis associated with organ dysfunction, hypoperfusion or hypotension defined as:

- Hypotension:

○ $\mathrm{SBP}<90 \mathrm{mmHg}$ or

○ MAP $<70 \mathrm{mmHg}$ or

$\circ$ a SBP decrease $>40 \mathrm{mmHg}$

- Hypoperfusion:

o Obtundation

O Oliguria (urine output $<0.5 \mathrm{~mL} \cdot \mathrm{kg}^{-1} \cdot \mathrm{hr}^{-1}$ )

$\circ$ Lactic acidosis

- Organ dysfunction:

$\circ$ Arterial hypoxemia $\left(\mathrm{PaO}_{2} / \mathrm{F}_{\mathrm{I}} \mathrm{O}_{2}<300\right)$

○ Acute oliguria (urine output $<0.5 \mathrm{~mL} \cdot \mathrm{kg}^{-1} \cdot \mathrm{hr}^{-1}$ or $45 \mathrm{~mL}$ for at least $2 \mathrm{hr}$ )

$\circ$ Creatinine increase $\geq 0.5 \mathrm{mg} \cdot \mathrm{dL}^{-1}$

- Coagulation abnormalities (international normalized ratio $>1.5$ or activated partial thromboplastin time $>60 \mathrm{sec}$ )

- Hyperbilirubinemia (plasma total bilirubin $>4 \mathrm{mg} \cdot \mathrm{dL}^{-1}$ or $70 \mathrm{mmol} \cdot \mathrm{L}^{-1}$ )

- Ileus (absent bowel sounds)

$\circ$ Thrombocytopenia (platelet count $<100000 \mu \mathrm{L}^{-1}$ )



Fig. 2 a Reduced mean systemic pressure (Pms) is one of the mechanisms of hemodynamic instability in septic shock. Top Venous return (VR) curve and cardiac output (CO) combined with the Starling relationship. Both VR and $\mathrm{CO}$ are equal at a specific right atrial pressure (Pra). The venous return is equal to the difference between the Pms and the Pra divided by the resistance to VR. The resistance to VR is a function of the slope of the VR. In septic shock, bacterial toxins and inflammatory cytokines lead to decreased peripheral resistance. Consequently, the Pms is reduced because the venous compliance is increased. Bottom Biventricular pressure-

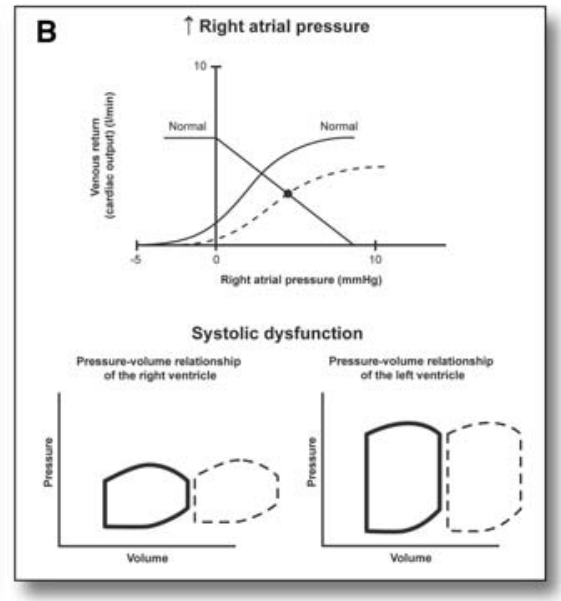

volume curves showing reduced stroke volume as a consequence of reduced VR and CO on both ventricles. b Top Myocardial depression with increased right atrial pressure (Pra) is the second mechanism of hemodynamic instability in septic shock. In septic shock, the inflammatory cytokines can impair ventricular systolic contraction, and consequently, Pra will increase with the associated reduction in $\mathrm{CO}$ and VR. Bottom Biventricular pressure-volume curves demonstrating the effects of impaired ventricular contractility and reduced ejection fraction. Systolic dysfunction will result in a right-sided shift of the pressure-volume relationship 


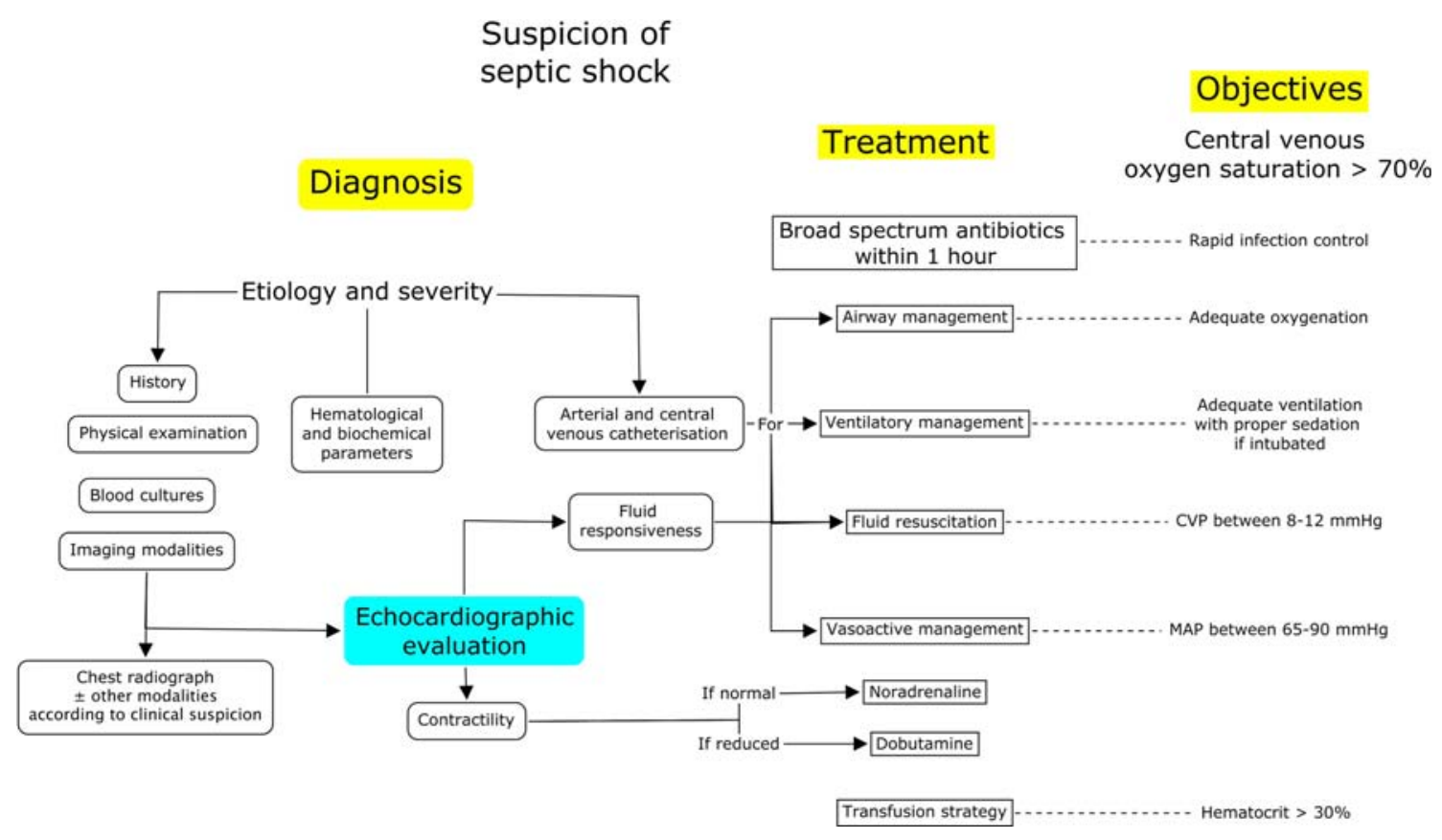

Fig. 3 Algorithm describing early goal-directed therapy paired with diagnostic techniques for the management of septic shock. $C V P$ central venous pressure, MAP mean arterial pressure

levels, mixed venous oxygen saturation, and the venoarterial carbon dioxide gradient. ${ }^{8}$ Various studies have shown that use of either norepinephrine or dopamine is appropriate to counteract vasodilatation. Dobutamine can, in turn, offer inotropic support when low cardiac output is suspected after echocardiographic evaluation and/or ventricular filling pressure assessment. Other specific therapies include activated protein $\mathrm{C}$, corticosteroids, and immunoglobulins that require particular indications. ${ }^{9,10}$

In conclusion, the contemporary approach to septic shock should include echocardiographic assessment of cardiac function as part of the diagnostic evaluation and as a guide to therapy. Early diagnosis and aggressive intervention with the appropriate antibiotics, fluid therapy, and vasoactive agents are critical to enhancing the likelihood of a favourable outcome.

Competing interests None declared.

\section{References}

1. Russell JA. Management of sepsis. N Engl J Med 2006; 355: 1699-713.
2. Vieillard-Baron A, Caille V, Charron C, Belliard G, Page B, Jardin $F$. Actual incidence of global left ventricular hypokinesia in adult septic shock. Crit Care Med 2008; 36: 1701-6.

3. Mitsuo T, Shimazaki S, Matsuda H. Right ventricular dysfunction in septic patients. Crit Care Med 1992; 20: 630-4.

4. Regueira T, Bruhn A, Hasbun P, et al. Intra-abdominal hypertension: incidence and association with organ dysfunction during early septic shock. J Crit Care 2008; 23: 461-7.

5. Kumar A, Roberts D, Wood KE, et al. Duration of hypotension before initiation of effective antimicrobial therapy is the critical determinant of survival in human septic shock. Crit Care Med 2006; 34: 1589-96.

6. Rivers E, Nguyen B, Havstad S, et al. Early goal-directed therapy in the treatment of severe sepsis and septic shock. N Engl J Med 2001; 345: 1368-77.

7. Dellinger RP, Levy MM, Carlet JM, et al. Surviving Sepsis Campaign: international guidelines for management of severe sepsis and septic shock: 2008. Crit Care Med 2008; 36: 296-327.

8. Johnson BA, Weil MH. Redefining ischemia due to circulatory failure as dual defects of oxygen deficits and of carbon dioxide excesses. Crit Care Med 1991; 19: 1432-8.

9. Bernard GR, Vincent JL, Laterre PF, et al. Efficacy and safety of recombinant human activated protein $\mathrm{C}$ for severe sepsis. N Engl J Med 2001; 344: 699-709.

10. Darenberg J, Ihendyane $N$, Sjolin J, et al. Intravenous immunoglobulin $G$ therapy in streptococcal toxic shock syndrome: a European randomized, double-blind, placebo-controlled trial. Clin Infect Dis 2003; 37: 333-40. 